\title{
Contrasts in the capacity and underlying mechanisms for compensatory growth in two pelagic marine fishes
}

\author{
Susan M. Sogard*, Bori L. Olla \\ Alaska Fisheries Science Center, National Marine Fisheries Service, Hatfield Marine Science Center, Newport, \\ Oregon 97365, USA
}

\begin{abstract}
The widespread capacity for teleost fishes to engage in compensatory growth suggests there are costs or trade-offs that constrain normal growth to sub-maximal rates. Some potential tradeoffs include behavioral conflicts between foraging and avoiding predators, and physiological aspects of energy allocation between synthesis of new tissue and functional demands of metabolism and maintenance. We examined the capacity for compensation and some potential underlying mechanisms in juveniles of 2 northern Pacific fish species, walleye pollock Theragra chalcogramma and sablefish Anoplopoma fimbria. Fish were deprived of food for 2 to $3 \mathrm{wk}$, then returned to ad libitum rations. Growth rates were subsequently compared to those for continually fed fish for up to 16 wk, and potential trade-offs in behavior (food consumption, routine swimming speeds, and response to a predator) and physiology (indexed by critical swimming speeds) were examined during 3 time periods: immediately after deprivation, after $4 \mathrm{wk}$ of ad libitum rations, and after $9 \mathrm{wk}$. We distinguished between routine swimming speeds, which indicate volitional motor activity, and critical swimming speeds, which estimate physiological capacity by forcing fish to swim to exhaustion against an increasing current. Previously deprived walleye pollock exhibited a clear, sustained capacity for accelerated growth, allowing them to quickly catch up in size to continually fed fish. Sablefish, however, exhibited only a minor level of growth compensation. Underlying mechanisms of compensatory growth also differed between the 2 species. Previously deprived walleye pollock increased food consumption to levels 3 to $4 \times$ greater than those of control fish and reduced energy expenditure by lowering routine swimming speeds. Compensating sablefish did not differ from control fish in consumption rates or routine swimming, but had lower critical swimming speeds than control fish, suggesting a trade-off in energy allocation. Responses to a simulated predator threat did not differ between previously deprived and continually fed fish of either species. The experimental results are suggestive of different mechanisms, behaviorally based for walleye pollock and physiologically based for sablefish, associated with accelerated growth. The differences between the 2 species in integrated processes of growth, behavior, and physiology are likely to be a function of their contrasting life history strategies and different baseline growth rates.
\end{abstract}

KEY WORDS: Ecological trade-offs $\cdot$ Swimming performance $\cdot$ Behavior $\cdot$ Walleye pollock $\cdot$ Sablefish

\section{INTRODUCTION}

Compensatory growth is a common phenomenon in a broad suite of plants and animals (Jobling et al. 1994, Arendt 1997). The process involves a phase of acceler-

${ }^{*}$ Present address: Southwest Fisheries Science Center, National Marine Fisheries Service, 110 Shaffer Road, Santa Cruz, California 95060. Email: susan.sogard@noaa.gov ated growth following a period of reduced growth, typically induced by food deprivation or lowered temperatures (e.g. Nicieza \& Metcalfe 1997). Engaging in accelerated growth often allows an individual to catch up in body size to conspecifics that have not experienced depressed growth. The capability for compensatory growth has intrigued ecologists because of its implication that growth is not always maximized, with individuals typically growing at rates below those that 
are physiologically possible. Thus, even under optimal environmental conditions there appear to be constraints on growth, or the existence of some type of reserve that is activated only under certain conditions. Conservative growth is counter to the demonstrated importance of body size and growth rate for survival, particularly in early life stages. For teleost fishes, much of the variability in population abundance is thought to be generated during the larval and early juvenile stages, with higher survival probabilities for individuals that are larger, have faster growth rates, or faster development times than other members of a cohort (e.g. Hare \& Cowen 1997). Understanding these mechanisms of selective mortality has driven much of the research on population dynamics of fishes (e.g. Houde 1987, Miller et al. 1988, Leggett \& Deblois 1994), and there is substantial evidence of survival advantages for large body size or rapid growth rates (Campana 1996, Meekan \& Fortier 1996, Sogard 1997). However, the widespread occurrence of compensatory growth suggests that growth rates are rarely maximal.

A number of potential trade-offs or costs have been proposed to account for less than maximal growth. Trade-offs can be categorized as physiological or behavioral in context. Physiological trade-offs include the well-documented switch in allocation between growth and reproduction for mature organisms (Roff 1992). For immature animals, Arendt (1997) proposes a similar conflict in allocation of available energy, with rapid growth coming at a cost of reduced rates of tissue repair and other maintenance functions. Rapidly growing salmonids, for example, have reduced rates of protein turnover compared to fish growing at moderate rates (McCarthy et al. 1994, Morgan et al. 2000). Conover \& Schultz (1997) propose a physiological trade-off between food consumption and metabolic scope: large meal sizes elevate metabolic rates due to the heat increment of feeding (specific dynamic action) to a greater extent than small meals. If food processing uses all of the available metabolic scope, the individual may be unable to engage motor activity rates sufficient to evade a predator (Billerbeck et al. 2001, Lankford et al. 2001). In addition to the immediate energetic costs of food processing, there is evidence that fast-growing individuals have reduced swimming capabilities even in a non-digestive state. A negative correlation between growth and swimming performance has been observed for fathead minnows (Kolok \& Oris 1995), Atlantic silversides (Billerbeck et al. 2001), rainbow trout (Gregory \& Wood 1998, 1999), and coho salmon (Farrell et al. 1997). The latter study is particularly insightful as it found that genetic alteration of coho salmon increased their growth rate but decreased their swimming performance, demonstrating a clear physiological trade-off in energy allocation.
Behavioral trade-offs resulting in less than maximal growth rates have also been documented, and primarily involve shifts in habitat or reduced foraging activity, resulting in lower food consumption or reduced food quality, but with the benefit of reduced predation risk or reduced competition (Lima \& Dill 1990, Sogard 1994). Such behavioral trade-offs suggest that animals sacrifice rapid growth to reduce their exposure to predators. Individuals that have fallen behind on a presumed growth trajectory may take greater risks in their habitat selection or foraging behavior, thereby improving growth but at a higher probability of being discovered by a predator. Damsgaard \& Dill (1998), for example, found that compensating coho salmon habituated faster to a predator threat and were more likely to utilize risky food patches than non-deprived fish growing at normal rates.

In the present study we tested for the occurrence of compensatory growth and examined potential underlying mechanisms in 2 fish species, walleye pollock Theragra chalcogramma and sablefish Anoplopoma fimbria. Both are pelagic as juveniles, have similar geographic ranges, similar diets, and similar social behavior (i.e. both form loose aggregations or shoals as juveniles). They differ markedly, however, in their baseline growth rates. Maximal growth rates of Age 0 walleye pollock are around $1.0 \mathrm{~mm} \mathrm{~d}^{-1}$ in length and $5 \% \mathrm{~d}^{-1}$ for specific growth in weight for a 1 to $2 \mathrm{~g}$ fish, based on a broad range of experiments in our laboratory (S. M. Sogard \& B. L. Olla unpubl. data). In contrast, Age 0 sablefish can exhibit rates of up to $3.0 \mathrm{~mm}$ $\mathrm{d}^{-1}$ and $11 \% \mathrm{~d}^{-1}$ in weight for a 1 to $2 \mathrm{~g}$ fish (Sogard \& Olla 2001). We compared growth rates of fish deprived of food for 2 to $3 \mathrm{wk}$ and of fish fed continually for up to $16 \mathrm{wk}$ after deprived fish were returned to ad libitum rations. We used critical swimming speeds to examine physiological trade-offs with growth. Behavioral tradeoffs were estimated by measuring consumption rates and examining risk-taking behavior during a simulated predator attack. Physiological and behavioral indices were measured immediately after a period of food deprivation, then 4 and 9 wk after fish were returned to ad libitum rations. These indices were compared to fish that were maintained on ad libitum rations throughout the experiments.

We hypothesized that (1) individuals undergoing compensatory growth would have reduced swimming performance, exhibit greater risk-taking behavior, and/or consume more food than fish growing at normal rates under constant feeding conditions, and (2) the extremely rapid baseline growth rate of sablefish would leave them with little in the way of energy reserves or potential mechanisms to further increase their growth, while the moderate growth rate of walleye pollock would allow a greater capacity for compensation. 


\section{MATERIALS AND METHODS}

Growth experiments. To test for the occurrence of compensatory growth, we conducted growth experiments for both species, with each experiment analyzed separately (Table 1). Fish were captured in the field as juveniles ( 30 to $50 \mathrm{~mm}$ total length, TL), maintained in 3401 laboratory tanks with flow-through seawater at ambient temperatures, and fed daily with an ad libitum ration of BioDiet pellets scattered across the water surface. They were held in these conditions for 1 to $3 \mathrm{mo}$ prior to experiments.

Sablefish growth was measured in 1995 using circular tanks (122 cm diameter, $340 \mathrm{l})$ maintained on a flow-through system at ambient temperatures (range = 10 to $16^{\circ} \mathrm{C}$, mean $=13^{\circ} \mathrm{C}$ ). Fish were held in groups of 3 to allow natural social interactions. There were 2 treatments (fish that were continually fed an ad libitum ration and fish that were deprived of food for $3 \mathrm{wk}$, then returned to an ad libitum ration for the remainder of the 16 wk experiment) with 4 replicate groups of each. Because sablefish used in the 1995 experiment were relatively large $($ mean $=119 \mathrm{~mm} \mathrm{TL})$, a second growth experiment was conducted for sablefish in 1998, using fish that were initially smaller in size $($ mean $=63 \mathrm{~mm} \mathrm{TL})$. Fish were held in groups of 3 in $174 \mathrm{l}(53 \mathrm{~cm}$ diameter) tanks in a partial flow-through system, with temperatures maintained at $12^{\circ} \mathrm{C}$. The treatments were comparable to those used in the 1995 experiment except the period of food deprivation was only $2 \mathrm{wk}$, with the assumption that a shorter time period would provide a comparable decline in body weight for the smaller fish. There were 7 replicate groups of each treatment and the experiment ran for $18 \mathrm{wk}$. Walleye pollock growth was measured in 1997 using the same experimental design as that of the 1998 sablefish experiment, with water temperature main- tained at $12^{\circ} \mathrm{C}$. Mean initial size of the fish was $94 \mathrm{~mm}$ TL. There were 11 replicate groups of each treatment and the experiment continued for $18 \mathrm{wk}$.

In all 3 experiments, fish were fed BioDiet pellets, with a composition of $45 \%$ protein, $15 \%$ fat, $8.5 \%$ carbohydrate, and $20.5 \%$ water. Daily rations were delivered with automatic feeders over the course of approximately $4 \mathrm{~h}$ to maximize food consumption. The food offered each day was never completely consumed, and we assumed that at the moderate temperatures used in the experiments $\left(11\right.$ to $\left.12^{\circ} \mathrm{C}\right)$ additional feeding would not have increased consumption. Uneaten food was siphoned from tanks every 2 to $3 \mathrm{~d}$. Fish were measured at the beginning and end of the treatment set-up period, then every 2 to $3 \mathrm{wk}$ for the duration of an experiment. Absolute growth in length $\left(\mathrm{mm} \mathrm{d}^{-1}\right)$ and specific growth in weight $\left[\left\{\log _{e}\left(\right.\right.\right.$ final weight)- $\log _{e}$ (initial weight) $\} / \mathrm{d} \times 100$ ] were calculated for each individual in a tank and the mean values for each tank determined for each time interval; thus, the tank means were used as replicates in statistical analyses.

We used repeated-measures ANOVA for each experiment to test for the effects of treatment (between groups factor) and time interval (within groups factor) on growth. Because specific growth rates declined with body size, it was necessary to adjust for the effect of different body sizes within a time interval. For example, previously deprived fish may have had a faster specific growth rate than continuously fed fish simply because they were smaller at the beginning of a time interval; this would not be attributable to compensatory growth. To allow comparison of treatments within a time interval, a regression of specific growth vs $\log _{\mathrm{e}}$ (initial weight) was calculated for all fish in the control group of each species. Individual growth scores were then calculated as the residual of specific growth rate from the expected value based on the fish's initial

Table 1. Outline of design for experiments testing compensatory growth, behavioral responses, and critical swimming speeds for juvenile walleye pollock and sablefish. Temperature: mean (SD); Initial size: means

\begin{tabular}{|c|c|c|c|c|c|c|c|}
\hline & \multirow[t]{2}{*}{ Year } & \multirow{2}{*}{$\begin{array}{l}\text { No. of } \\
\text { replicates }\end{array}$} & \multirow{2}{*}{$\begin{array}{l}\text { Fish per } \\
\text { replicate }\end{array}$} & \multirow{2}{*}{$\begin{array}{l}\text { Deprivation } \\
\text { period (wk) }\end{array}$} & \multirow{2}{*}{$\begin{array}{l}\text { Temperature } \\
\left({ }^{\circ} \mathrm{C}\right)\end{array}$} & \multicolumn{2}{|c|}{ Initial size: } \\
\hline & & & & & & $\mathrm{TL}(\mathrm{mm})$ & Wet wt $(\mathrm{g})$ \\
\hline \multicolumn{8}{|c|}{ Growth experiments } \\
\hline Sablefish & 1995 & 4 & 3 & 3 & $13.0(1.64)$ & 119 & 10.89 \\
\hline Sablefish & 1998 & 7 & 3 & 2 & $12.0(0.5)$ & 63 & 1.54 \\
\hline Walleye pollock & 1997 & 11 & 3 & 3 & $11.5(0.6)$ & 94 & 7.31 \\
\hline \multicolumn{8}{|c|}{ Behavior experiments } \\
\hline Sablefish & 1998 & 8 & 2 & 2 & $11.9(0.86)$ & 79 & 3.24 \\
\hline Walleye pollock & 1999 & 10 & 2 & 3 & $11.5(1.03)$ & 73 & 2.90 \\
\hline \multicolumn{8}{|c|}{ Critical swimming speed experiments } \\
\hline Sablefish & 1998 & 8 & 2 & 2 & $11.9(0.86)$ & 78 & 3.01 \\
\hline Walleye pollock & 1999 & 10 & 2 & 3 & $11.5(1.03)$ & 73 & 2.90 \\
\hline
\end{tabular}


size during each time interval. Corresponding statistical tests had a degree of freedom removed to adjust for the use of residuals. Growth in length was not a function of initial size for either species, allowing direct comparison of absolute growth rates between treatments. Post-hoc tests following the repeated measures ANOVAs were used to compare treatment effects within each time interval.

In order to evaluate the pattern of catch-up growth for each species, we used paired comparison $t$-tests within each time period. Pairs were ordered according to average size of fish in a tank. This method was used to control for differences in mean size across groups within a treatment. At the beginning of an experiment, mean sizes were closely matched between treatments. They diverged significantly during the treatment period, and the paired comparison $t$-tests were used to indicate when the previously deprived groups no longer differed in size from the control groups (i.e. growth compensation was completed). To reduce the Type II error associated with this analysis (i.e. falsely concluding that deprived fish were no longer smaller than control fish), we chose a conservative significance level of $p=0.1$.

Behavior experiments. Experiments testing for a behavioral response to a period of food deprivation were conducted in 1998 for sablefish and in 1999 for walleye pollock (Table 1). Experiments were conducted at 3 different time periods, immediately following a period of food deprivation ( $2 \mathrm{wk}$ for sablefish, 3 wk for walleye pollock), then 4 and 9 wk after treatment fish had been returned to ad libitum rations. Different periods of deprivation were used to provide comparable separation between treatments for the 2 species. After a 3 wk treatment period, deprived walleye pollock had on average lost $13 \%$ of their initial body weight and were $39 \%$ of the weight of control fish. For sablefish, 2 wk of deprivation resulted in an average loss of $10 \%$ of the initial weight, and fish weights were $42 \%$ of control fish weights. Daily feeding was identical to that used in the growth experiments, with ad libitum rations of BioDiet pellets delivered by automatic feeders over $4 \mathrm{~h}$. In each period there were 8 replicate groups of 2 fish each for sablefish and 10 replicate groups of 2 fish each for walleye pollock. Fish were observed in pairs to allow natural social interactions.

The day before a behavior trial, fish were removed from holding tanks and placed in observation tanks (340 l volume, $121 \mathrm{~cm}$ diameter). They were allowed to acclimate overnight. On the following day, they were videotaped for $2 \mathrm{~h}$ using overhead cameras that were operated remotely. During taping, fish received food from automatic feeders positioned over the side of the tank. An ad libitum ration of food pellets dropped con- tinuously into the water near the tank edge over a $2 \mathrm{~h}$ period. After fish had received food for $30 \mathrm{~min}$, they were disturbed by a simulated predator threat. The threat consisted of a fish-shaped, large-eyed model predator suspended from a pole. The model was plunged into observation tanks directly beneath the feeder by a concealed researcher, then swirled around in a small circle within the area of food delivery for $5 \mathrm{~s}$. It was removed and the fish were left undisturbed for the remaining 90 min of videotaping.

Two behavioral measures were acquired from the videotapes. During playback, the circular tank image was divided into 4 equal quadrants, with the feeder positioned in the center of 1 quadrant. The percentage of time spent in the feeder quadrant was determined by noting the position of both fish in a pair every $10 \mathrm{~s}$ for a 2 min period. Routine swimming speeds were determined using an image analysis system in which fish movements were traced with a digitizing pen on a video monitor. Each individual of a pair was traced for $30 \mathrm{~s}$ and the mean swimming speed determined. For each group, observations of time spent in the feeder quadrant and routine swimming behavior were conducted at 7 time intervals: 20 and 10 min before the model presentation, and 2, 10, 20, 30, and 60 min after the predator threat. All measures within a time period were averaged for each group prior to data analysis, and the 2 pre-threat observations were averaged to form a single 'before' index.

Statistical analyses were conducted separately for each species. Repeated measures ANOVA tested the effect of treatment, period (between groups factors), and time interval (within groups factor) on each of the behavioral variables. Comparison of normal probability plots of the raw data and evaluation of variances among ration and time treatments indicated that parametric tests were appropriate for all analyses. Results indicating significant effects of time interval on behavior were subsequently analyzed with Dunnett's test $(\alpha=0.05)$ comparing each post-threat observation to the pre-threat observation. This analysis allowed us to estimate any recovery of behavior to pre-threat levels during the hour after the threat.

At the conclusion of videotaping, fish were measured and immediately preserved in $95 \%$ ETOH. One fish from each pair was dissected and the gut contents removed to a weighing pan. The carcass and gut contents were dried to a constant weight at $80^{\circ} \mathrm{C}$ and the percentage of its dry weight consumed during the $2 \mathrm{~h}$ time period was determined. Gut content percentages were compared between control and deprived treatments within each time period using $t$-tests. Power analyses of these tests were used to determine the minimum difference in means detectable at a power level of 0.80 . 
Critical swimming speeds. Critical swimming speeds were measured in a Blazka-type chamber, with fish swimming against a propellor-driven current until fatigued. The inner chamber was an acrylic tube $60 \mathrm{~cm}$ long and $9.5 \mathrm{~cm}$ in diameter. Baffles constructed of plastic drinking straws acted as flow straighteners at either end of the tube. A flowthrough water supply maintained temperatures at ambient levels (range across all trials $=10$ to $15^{\circ} \mathrm{C}$, mean $=11.5^{\circ} \mathrm{C}$ for walleye pollock and $11.9^{\circ} \mathrm{C}$ for sablefish).

For a trial, individual fish were placed in the chamber and allowed to acclimate for $30 \mathrm{~min}$ in a moderate current of $10 \mathrm{~cm} \mathrm{~s}^{-1}$. The current speed was then gradually increased to $20 \mathrm{~cm} \mathrm{~s}^{-1}$ and maintained at that speed for $10 \mathrm{~min}$. The current was increased stepwise by $10 \mathrm{~cm} \mathrm{~s}^{-1}$ every $10 \mathrm{~min}$ until fish stopped swimming and fell back against the rear baffle. If the fish did not recover and return to swimming within $1 \mathrm{~min}$, the trial was terminated. The time of failure was noted and the critical swimming speed calculated following Brett (1964):

$$
U_{c r i t}=u_{\mathrm{i}}+\left(\frac{t_{\mathrm{i}}}{t_{\mathrm{ii}}} \times u_{\mathrm{ii}}\right)
$$

where $u_{\mathrm{i}}$ is the highest velocity achieved, $u_{\mathrm{ii}}$ is the velocity increment $\left(10 \mathrm{~cm} \mathrm{~s}^{-1}\right), t_{\mathrm{i}}$ is the time spent at the final velocity before failure, and $t_{\text {ii }}$ is the time interval (10 min).

Fish from the control and deprived treatments were tested in each of the 3 time periods $(0,4$, and 9 wk after deprived fish were returned to ad libitum rations). Fish were tested only once and had not been used in any other experiments. There were 8 sablefish replicates and 10 walleye pollock replicates for each treatment/time period combination (Table 1). Due to their extremely rapid growth rates, sablefish were too large in body size to allow proper functioning of the swimming chamber in Period 3; thus, results for this species are only reported for Periods 1 and 2.

Because swimming speed is a function of fish size, analysis of critical swimming speeds utilized residuals from a regression of $U_{\text {crit }}$ on total length for control fish. The regression was calculated separately for each species from swimming performance tests for control fish across all time periods. Individual scores were calculated as the residual of $U_{\text {crit }}$ from the expected values based on the fish's total length. Residual scores of food-deprived fish were compared to control fish for each time period with $t$-tests. A degree of freedom was subtracted for each test to adjust for the use of residuals. Power analyses were applied to determine the effect size detectable at a power level of 0.80 .

\section{RESULTS}

\section{Growth experiments}

Walleye pollock demonstrated a clear capacity for compensatory growth. After the deprived fish were returned to an ad libitum ration, they grew faster in weight than control fish for the next 4 time intervals (up to $9 \mathrm{wk}$ after re-feeding; Fig. 1). Accelerated growth was evident for both specific growth rates and residual scores that adjusted for initial weight. Growth in length of deprived fish during the initial re-feeding period continued to be lower than that of control fish, but matched that of controls by 3 to 4 wk after re-feeding, and then accelerated to a significantly faster rate by the 3rd post-deprivation time interval, with accelerated growth continuing up to 12 wk after re-feeding (Fig. 1). The largest differential was during the 3rd time interval ( 3 to $4 \mathrm{wk}$ after refeeding) for growth in weight, when treatment fish grew $65 \%$ faster than control fish, and during the 4 th time interval ( 5 to 6 wk after re-feeding) for growth in length,

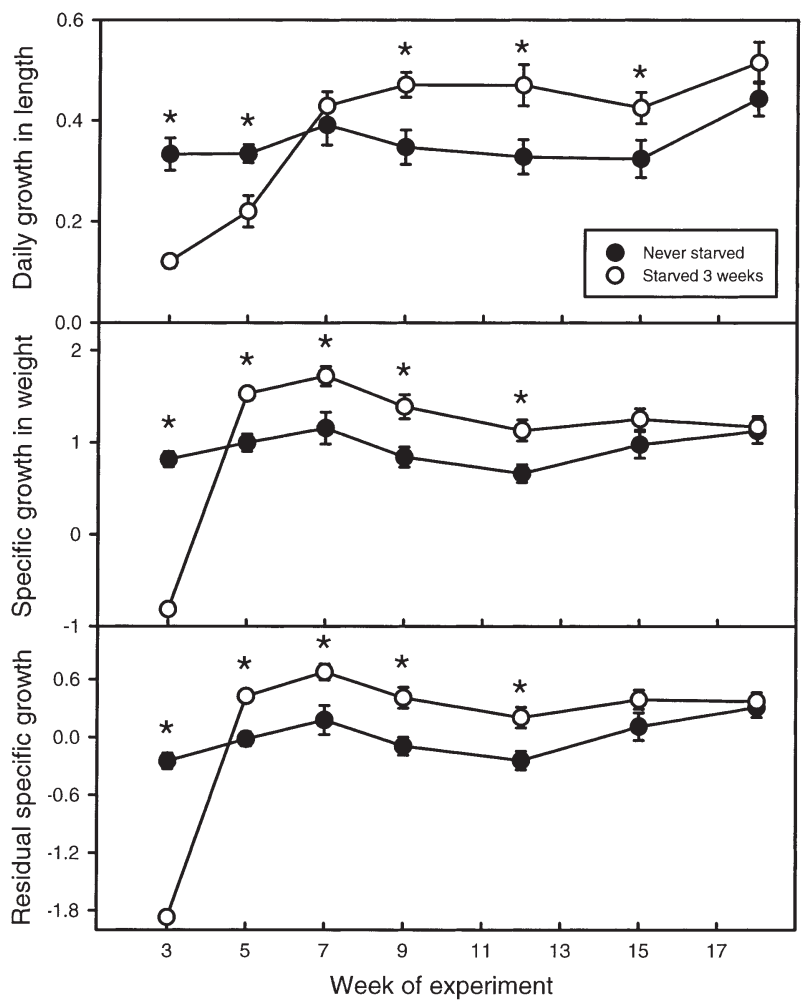

Fig. 1. Theragra chalcogramma. Mean (SE) growth rates given as total length $\left(\mathrm{mm} \mathrm{d}^{-1}\right)$, specific growth in wet wt (\% $\mathrm{d}^{-1}$ ), and residual specific growth after adjusting for initial wet wt. During the initial $3 \mathrm{wk}$, fish received either no food (O) or ad libitum rations $(\bullet)$. Subsequently, all fish received ad libitum rations. *: significant differences between treatments within a time interval, based on post-hoc contrasts following repeated measures ANOVA 


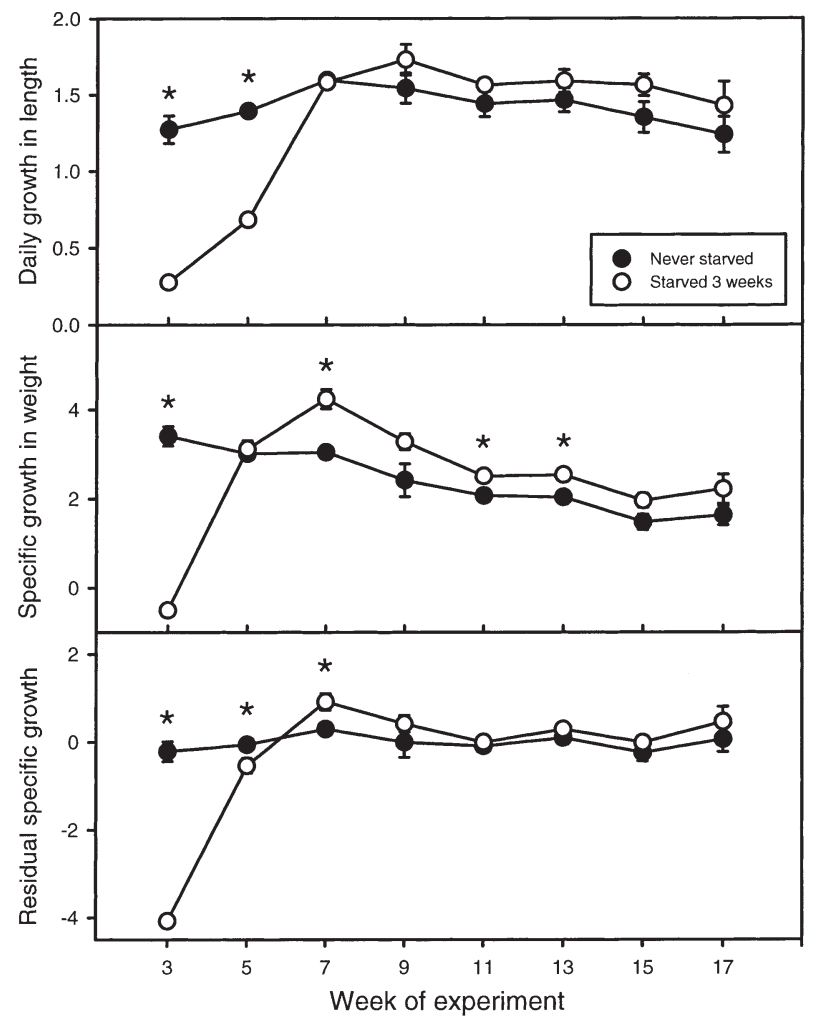

Fig. 2. Anoplopoma fimbria. Mean (SE) growth rates (1995 experiment) given as total length $\left(\mathrm{mm} \mathrm{d}^{-1}\right)$, specific growth in wet wt $\left(\% \mathrm{~d}^{-1}\right)$, and residual specific growth after adjusting for initial wet wt. During the initial $3 \mathrm{wk}$, fish received either no food (0) or ad libitum rations $(\bullet)$. Subsequently, all fish received ad libitum rations. *: significant differences between treatments within a time interval, based on post-hoc contrasts following repeated measures ANOVA

when treatment fish grew $43 \%$ faster than control fish. Repeated measures ANOVA reflected the shifting pattern of growth rates over time, with significant interactions between treatment and time period (for growth in length, $F_{1,20}$ for treatment $=0.83, \mathrm{p}=0.373 ; F_{6,120}$ for time period $=16.85, \mathrm{p}<0.001 ; F_{6,120}$ for the interaction $=$ 10.06, $\mathrm{p}<0.001$; for specific growth in weight, $F_{1,20}$ for treatment $=0.51, \mathrm{p}=0.305_{;} F_{6,120}$ for time period $=55.79$, $\mathrm{p}<0.001 ; F_{6,120}$ for the interaction $=39.91, \mathrm{p}<0.001 ;$ for residual growth in weight, $F_{1,19}$ for treatment $=1.13, \mathrm{p}=$ $0.301 ; F_{6,120}$ for time period $=65.24, \mathrm{p}<0.001 ; F_{6,120}$ for the interaction $=10.06, \mathrm{p}<0.001$ ).

Sablefish had a greatly reduced capacity for compensatory growth compared to walleye pollock. In the 1995 experiment, during the $14 \mathrm{wk}$ following the return to ad libitum rations, sablefish that had been deprived of food for $3 \mathrm{wk}$ were unable to accelerate growth in length to levels higher than exhibited by control groups (Fig. 2). Specific growth rates in weight of previously deprived fish were higher than those of control fish during 3 time periods. However, after adjusting for initial size in each

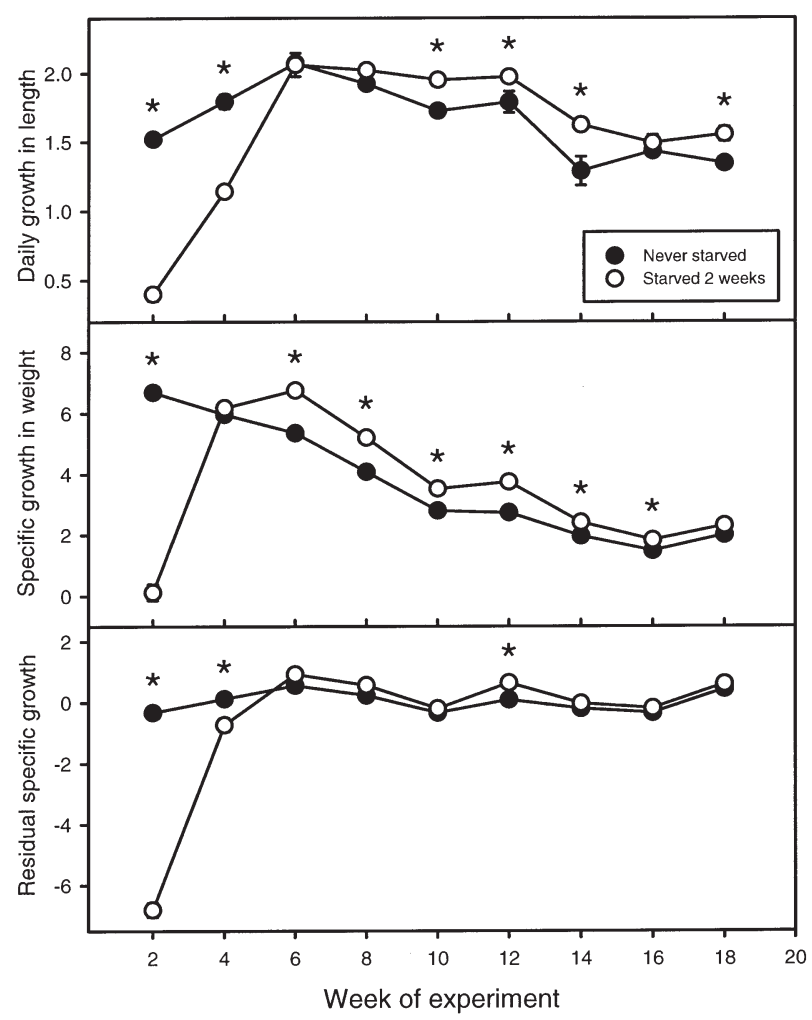

Fig. 3. Anoplopoma fimbria. Mean (SE) growth rates (1998 experiment) in total length $\left(\mathrm{mm} \mathrm{d}^{-1}\right)$, specific growth in wet wt $\left(\% \mathrm{~d}^{-1}\right)$, and residual specific growth after adjusting for initial wet wt. During the initial $2 \mathrm{wk}$, fish received either no food (0) or ad libitum rations $(\bullet)$. Subsequently, all fish received ad libitum rations. *: significant differences between treatments within a time interval, based on post-hoc contrasts following repeated measures ANOVA

time period, significantly faster growth by deprived fish was evident only during the 3rd time period (3 to $4 \mathrm{wk}$ after re-feeding). During this period specific growth rates were $39 \%$ higher for previously deprived groups compared to control fish. Repeated measures analyses indicated the expected significant interactions between treatment and time period (for growth in length, $F_{1,6}$ for treatment $=2.68, \mathrm{p}=0.153 ; F_{7,42}$ for time period $=35.15$, $\mathrm{p}<0.001 ; F_{7,42}$ for the interaction $=21.47, \mathrm{p}<0.001$; for specific growth in weight, $F_{1,6}$ for treatment $=0.10, \mathrm{p}=$ $0.763 ; F_{7,42}$ for time period $=32.46, \mathrm{p}<0.001 ; F_{7,42}$ for the interaction $=39.50, \mathrm{p}<0.001$; for residual growth in weight, $F_{1,5}$ for treatment $=4.20, \mathrm{p}=0.096 ; F_{7,42}$ for time period $=43.61, \mathrm{p}<0.001 ; F_{7,42}$ for the interaction $=$ 33.23, $\mathrm{p}<0.001)$.

Results of the 1998 sablefish experiment, which used smaller fish, suggested a slightly greater capacity for compensatory growth (Fig. 3). Significantly faster growth in length by previously deprived fish occurred in 4 of the 8 time periods after fish were returned to ad libitum rations. The greatest difference was 11 to $12 \mathrm{wk}$ 


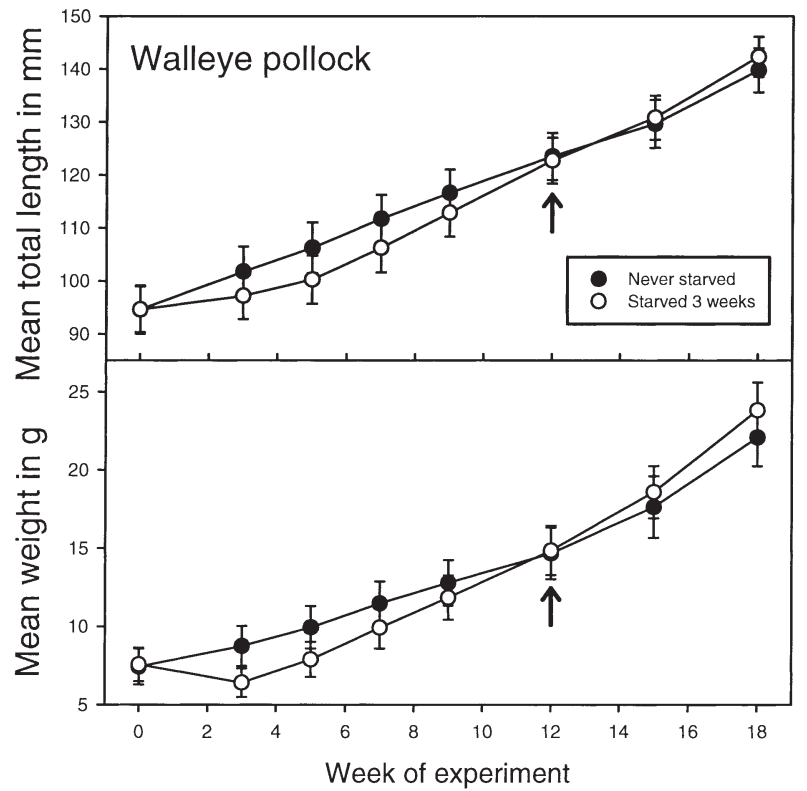

Fig. 4. Theragra chalcogramma. Size trajectories in mean total length (SE) and wet wt (SE) in the growth experiment. During the initial $3 \mathrm{wk}$, fish received either no food (O) or ad libitum rations $(\bullet)$. Subsequently, all fish received ad libitum rations. Arrows depict the time period in which the treatment groups were no longer significantly different $(p=0.1)$, based on paired comparison $t$-tests matching groups ordered by size within each treatment

after re-feeding, when previously deprived fish grew $26 \%$ faster than control fish. Significantly faster growth in weight, after adjusting for initial size, occurred in 1 of the 8 post-feeding periods. During the time interval of 9 to $10 \mathrm{wk}$ after re- feeding, previously deprived fish had specific growth rates (unadjusted for initial size) that were $37 \%$ faster than control fish. Repeated measures analyses again indicated significant interactions between treatment and time period (for growth in length, $F_{1,12}$ for treatment $=5.58, \mathrm{p}=0.036 ; F_{8,96}$ for time period $=88.40, \mathrm{p}<0.001 ; F_{8,96}$ for the interaction $=42.73$, $\mathrm{p}<0.001$; for specific growth in weight, $F_{1,12}$ for treatment $=5.72, \mathrm{p}=0.034 ; F_{8,96}$ for time period $=345.39$, $\mathrm{p}<0.001 ; F_{8,96}$ for the interaction $=194.56, \mathrm{p}<0.001$; for residual growth in weight, $F_{1,11}$ for treatment $=46.15$, $\mathrm{p}<0.001 ; F_{8,96}$ for time period $=263.95, \mathrm{p}<0.001 ; F_{8,96}$ for the interaction $=197.13, \mathrm{p}<0.001$ ).

The differences in compensatory capacity between the 2 species resulted in differences in the time frame of closing the gap in size between treatments. Deprived walleye pollock were able to catch up to control fish in both total length and wet weight 9 wk after being returned to ad libitum rations (Fig. 4), whereas deprived sablefish did not catch up to control fish in either length or weight during either experiment (Fig. 5). Sablefish in both experiments were gradually
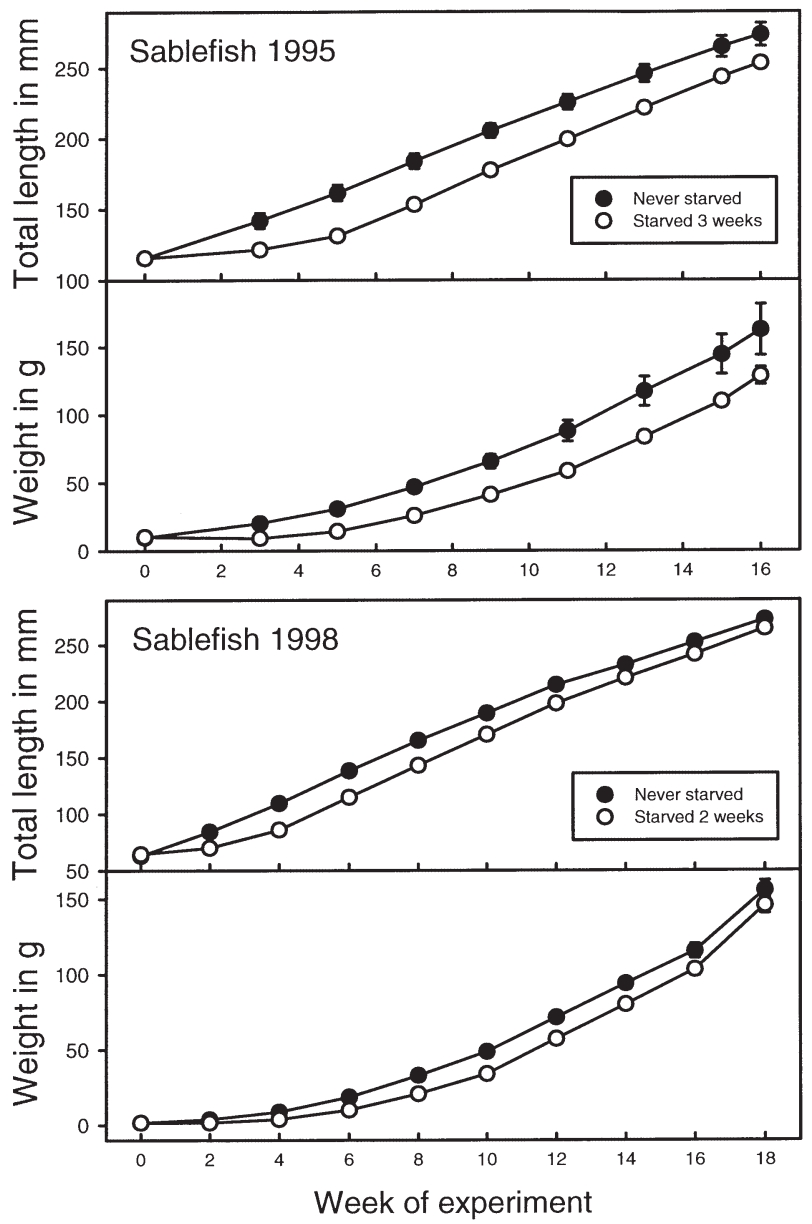

Fig. 5. Anoplopoma fimbria. Size trajectories in mean total length (SE) and wet wt (SE) for sablefish in 1995 and 1998 growth experiments. During the initial 2 to $3 \mathrm{wk}$, fish received either no food $(0)$ or ad libitum rations $(\bullet)$. Subsequently, all fish received ad libitum rations. Deprived fish remained significantly smaller than control fish in both length and weight at the end of both experiments, based on paired comparison $t$-tests $(\mathrm{p}=0.1)$

approaching a common size distribution, but presumably would have required several more weeks for full compensation to occur.

An interesting pattern observed in experiments for both species was continued growth in length during the initial starvation period. Deprived walleye pollock on average grew $0.12 \mathrm{~mm} \mathrm{~d}^{-1}$, sablefish in 1995 grew $0.28 \mathrm{~mm} \mathrm{~d}^{-1}$, and sablefish in 1998 grew $0.40 \mathrm{~mm} \mathrm{~d}^{-1}$ during the respective starvation periods.

\section{Behavior experiments}

When exposed to food after a $3 \mathrm{wk}$ period of deprivation, walleye pollock responded by spending more time in the vicinity of a feeder than continually fed con- 


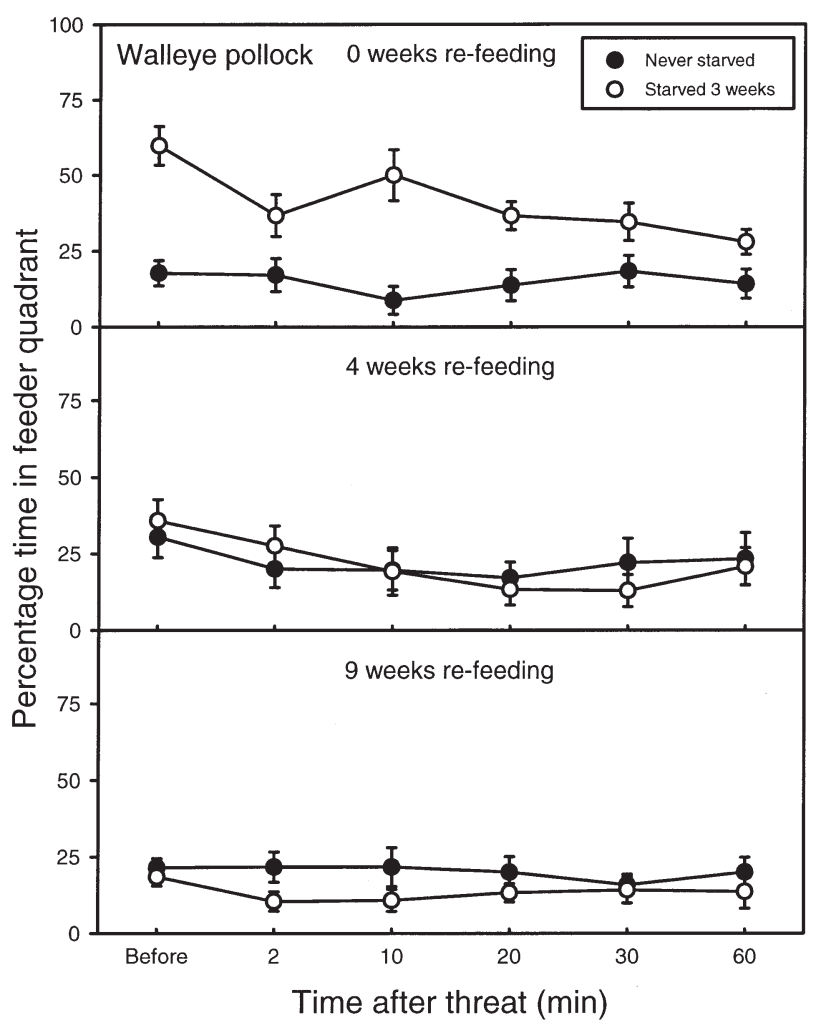

Fig. 6. Theragra chalcogramma. Mean percentage of time (SE) spent in the quadrant of observation tanks where food pellets entered from an automatic feeder during behavior experiments. Fish were either held on ad libitum rations prior to the experiment ( $\bullet$ ) or held without food for $3 \mathrm{wk}$, then returned to ad libitum rations ( $(0)$. Fish locations were measured before and after a simulated predator threat directly under the feeder. Experiments were conducted 0, 4, and 9 wk after deprived fish were returned to ad libitum rations

trol fish (Fig. 6, Period 1, repeated measures ANOVA, $F_{1,18}$ for treatment factor $\left.=30.88, \mathrm{p}<0.001\right)$. The difference between deprived and control fish was no longer evident for behavioral observations 4 wk after refeeding (Period 2, $F_{1,18}=0.01, \mathrm{p}=0.952$ ) and $9 \mathrm{wk}$ after re-feeding (Period 3, $F_{1,18}=1.93, \mathrm{p}=0.181$ ). Routine swimming speeds of deprived walleye pollock were significantly reduced compared to control fish in both Periods 1 and 2 (Fig. 7, repeated measures ANOVA, $F_{1,18}$ for Period $1=18.27, \mathrm{p}<0.001 ; F_{1,18}$ for Period $2=$ 13.03, $\mathrm{p}=0.002)$, but did not differ in Period $3\left(F_{1,18}=\right.$ $0.01, \mathrm{p}=0.942)$.

In contrast to walleye pollock, sablefish did not differ between treatments in their occurrence in the feeder quadrant (Fig. 8, ANOVA, p for all 3 periods > 0.05). For pre-threat observations, sablefish typically spent more time near the feeder (mean occurrence for the combined treatments $=54 \%$ in Period 1, 58\% in Period 2 , and $56 \%$ in Period 3 ) than pollock did (mean occurrence $=18 \%$ for control fish and $60 \%$ for deprived fish

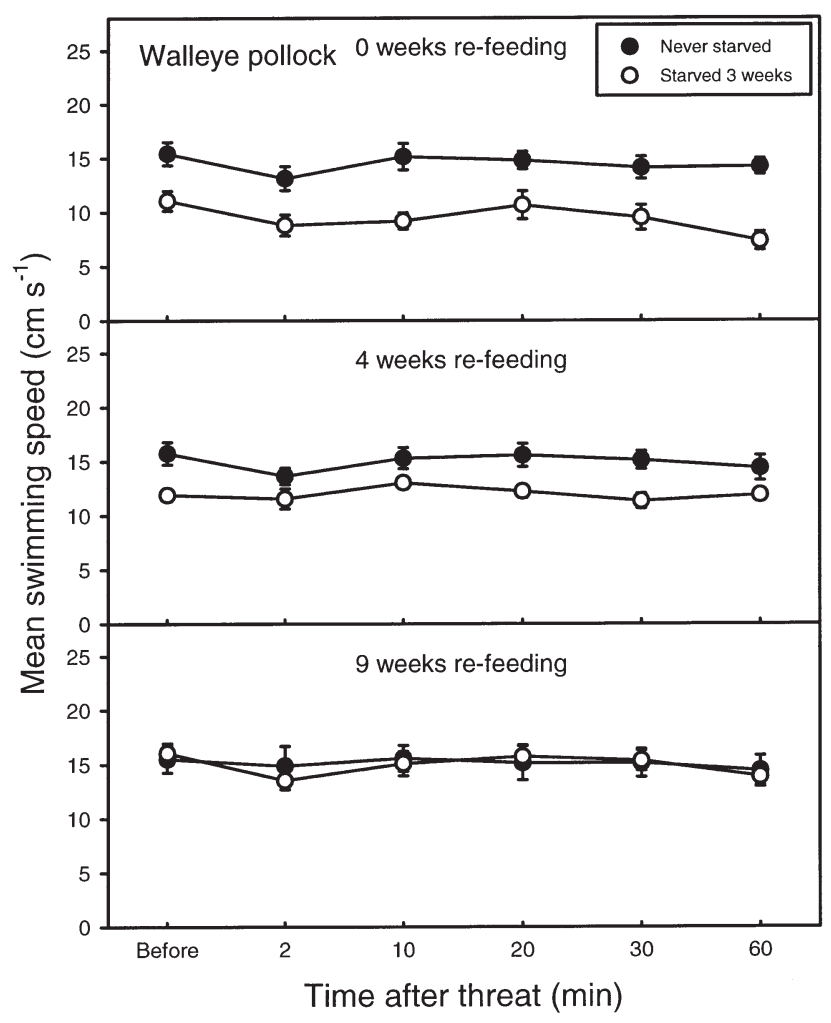

Fig. 7. Theragra chalcogramma. Mean routine swimming speed (SE) during the behavior experiment. Fish were either held on ad libitum rations prior to the experiment $(\bullet)$ or held without food for $3 \mathrm{wk}$, then returned to ad libitum rations (0). Swimming was measured before and after a simulated predator threat. Experiments were conducted 0, 4, and 9 wk after deprived fish were returned to ad libitum rations

in Period 1, $33 \%$ for the combined treatments in Period 2 , and $20 \%$ in Period 3). Deprived sablefish had lower routine swimming speeds than control fish immediately after the starvation period (Fig. 9, repeated measures ANOVA, $F_{1,14}=13.32, \mathrm{p}=0.003$ ), but there was no difference between treatments after 4 or $9 \mathrm{wk}$ of refeeding $(\mathrm{p}>0.05)$.

Walleye pollock displayed only a minimal response to a simulated predator threat. Control fish did not reduce their occurrence in the feeder quadrant following the threat in any of the 3 time periods (Fig. 6, repeated measures ANOVA, all $\mathrm{p}>0.05)$; thus, we could not compare recovery rates of deprived vs control fish. In Period 1, both treatments responded to the threat by initially reducing routine swimming speeds (Fig. 7, Dunnett's test, $\alpha=0.05$ ). However, both groups returned to pre-threat levels of swimming activity within 10 min after the predator model was displayed. There was no apparent response in Periods 2 or 3 by fish in either treatment; swimming speeds did not differ from pre-threat levels for any of the post-threat observations. 


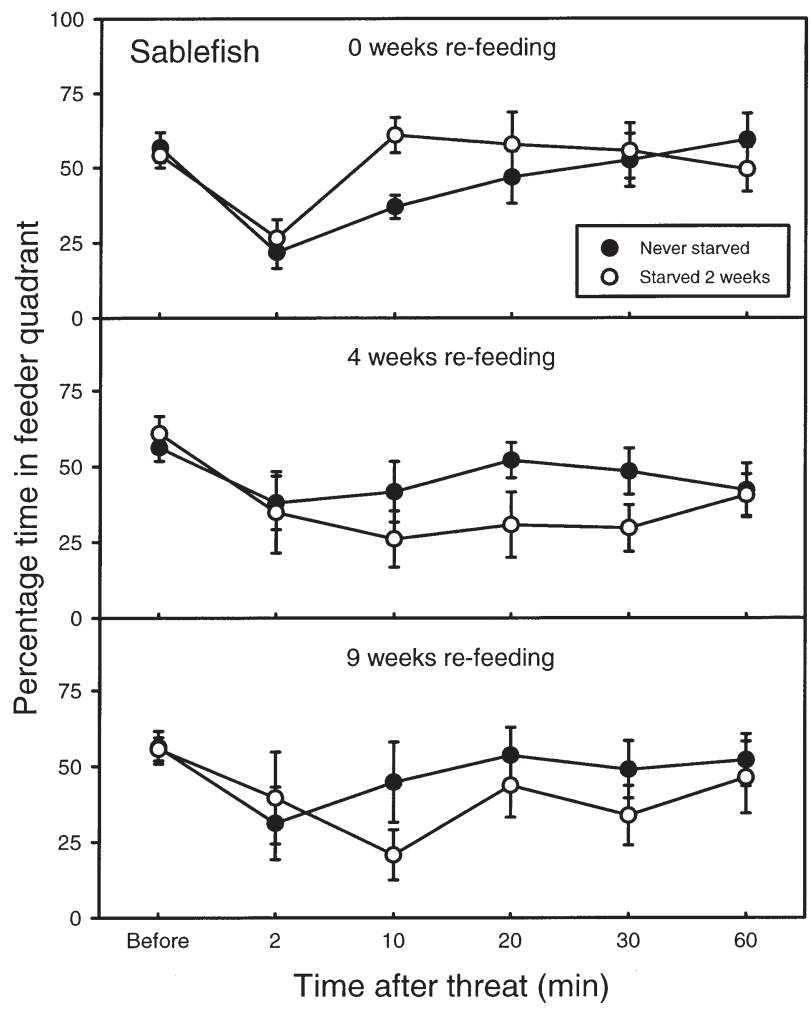

Fig. 8. Anoplopoma fimbria. Mean percentage of time (SE) spent in the quadrant of observation tanks where food pellets entered from an automatic feeder during behavior experiments. Fish were either held on ad libitum rations prior to the experiment $(\bullet)$ or held without food for $2 \mathrm{wk}$, then returned to ad libitum rations ( $(0)$. Fish locations were measured before and after a simulated predator threat directly under the feeder. Experiments were conducted 0,4 , and 9 wk after deprived fish were returned to ad libitum rations

Sablefish appeared to be more responsive to the simulated threat than walleye pollock. In Period 1, both deprived and continually fed fish reduced the time spent in the feeder quadrant immediately after the threat (Fig. 8, Dunnett's test, $\alpha=0.05$ ). Although deprived fish appeared to recover to pre-threat levels more quickly than control fish, there was no significant difference in the time spent in the feeder quadrant by either treatment during the observations 10 to $60 \mathrm{~min}$ after the threat. After 4 and 9 wk of re-feeding, occurrence in the feeder quadrant was highly variable among groups, and continuously fed fish did not have any significant reduction in time spent near the feeder after the threat. Thus, control fish recovered from avoidance of the threat location as quickly or more rapidly than deprived fish, counter to our predictions. Similar results were observed for routine swimming speeds. Both control and deprived fish significantly reduced swimming speeds immediately following the predator threat in all 3 time periods (Fig. 9, Dunnett's test, all $\alpha<0.01$ ), but recovery to pre-threat levels was variable and inconsistent be-

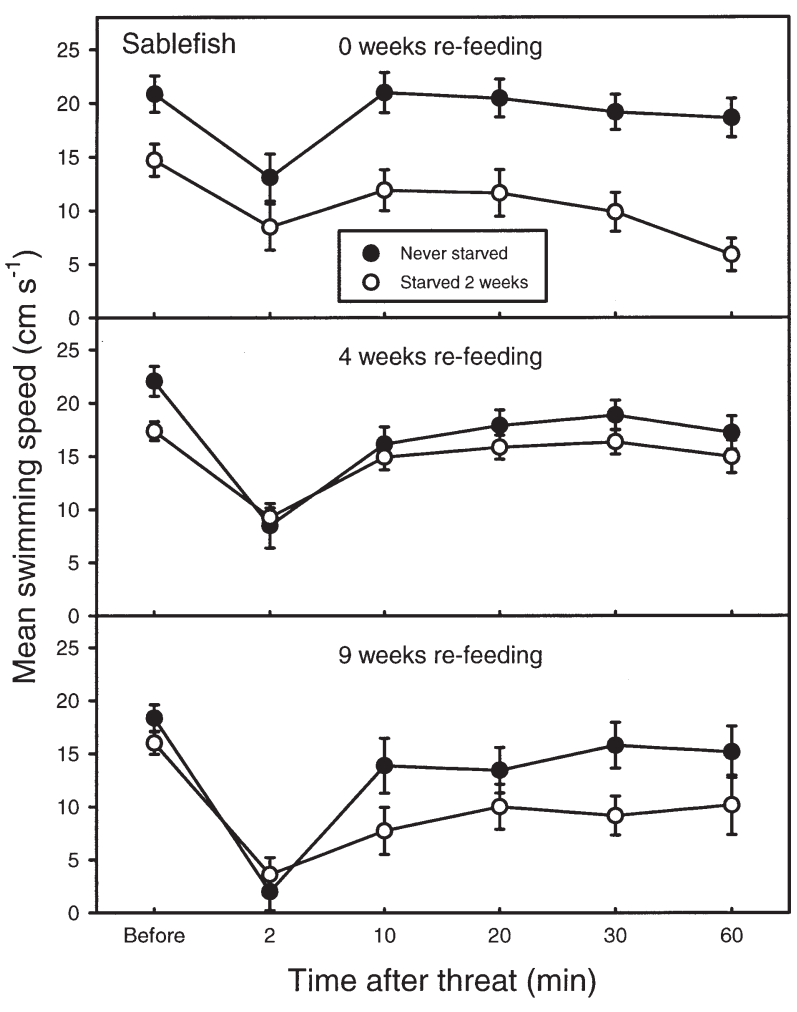

Fig. 9. Anoplopoma fimbria. Mean routine swimming speed (SE) during the behavior experiment. Fish were either held on ad libitum rations prior to the experiment $(\bullet)$ or held without food for $2 \mathrm{wk}$, then returned to ad libitum rations (0). Swimming was measured before and after a simulated predator threat. Experiments were conducted 0, 4, and 9 wk after deprived fish were returned to ad libitum rations

tween treatments, again not supporting our hypothesis of more rapid recovery by deprived fish.

Sablefish and walleye pollock differed markedly in their consumption of food during the behavioral observations (Fig. 10). Sablefish consumed relatively more food than walleye pollock during the $2 \mathrm{~h}$ trials and there was no difference between treatments for sablefish during any of the 3 time periods ( $t$-tests, all $p>0.05$, effect size detectable at a power level of 0.80 $=4$ in all 3 experiments). Walleye pollock, in contrast, consumed more than $3 \times$ as much food as control fish immediately after deprivation $\left(t_{18}=2.986, p=0.008\right)$, almost $4 \times$ as much $4 \mathrm{wk}$ after being returned to ad libitum rations $\left(t_{18}=3.347, \mathrm{p}=0.004\right)$, and similar levels after $9 \mathrm{wk}$ of re-feeding $\left(t_{18}=0.587, \mathrm{p}=0.564\right.$, detectable effect size at power $0.80=0.2$ ).

\section{Critical swimming speeds}

Mean critical swimming speeds ranged from 35 to $60 \mathrm{~cm} \mathrm{~s}^{-1}$ for sablefish, depending on body size and ex- 


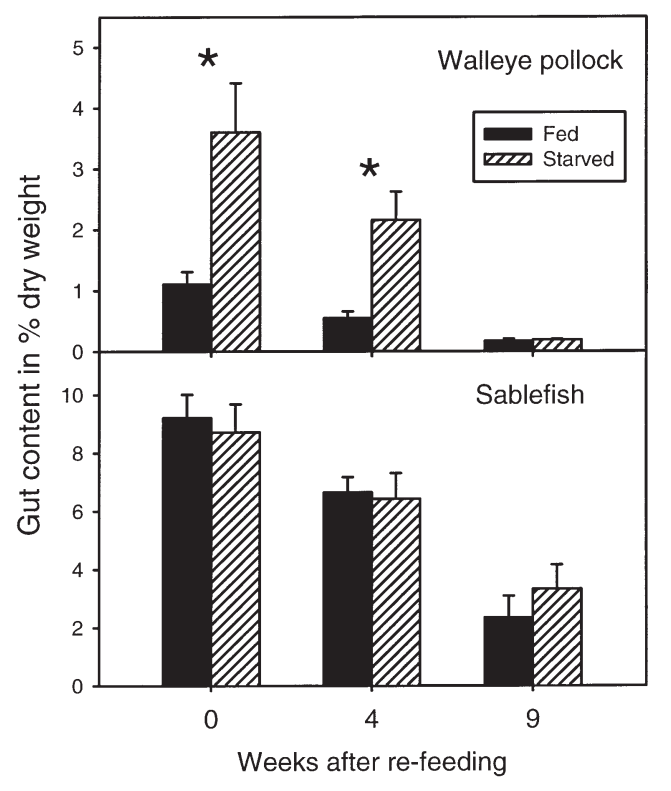

Fig. 10. Theragra chalcogramma and Anoplopoma fimbria. Mean weight (SE) of gut contents on a \% dry wt basis consumed by walleye pollock and sablefish during $2 \mathrm{~h}$ behavior experiments. *: significant differences between treatments within a time period based on $t$-tests. Fish were either held on ad libitum rations prior to the experiment (solid bars) or held without food for 2 to $3 \mathrm{wk}$, then returned to ad libitum rations (striped bars). Experiments were conducted 0, 4, and 9 wk after deprived fish were returned to ad libitum rations

perimental treatment, and from 32 to $57 \mathrm{~cm} \mathrm{~s}^{-1}$ for walleye pollock. After adjusting for body size using residuals, critical swimming speeds of both sablefish and walleye pollock were significantly reduced for deprived fish compared to control fish during Period 1 (Fig. $11, t_{14}$ for sablefish $=3.186, p=0.006 ; t_{18}$ for walleye pollock $=3.127, \mathrm{p}=0.006$ ). At this time, deprived fish had not received food for $2 \mathrm{wk}$ (sablefish) or $3 \mathrm{wk}$ (walleye pollock) prior to testing in the swimming chamber. After fish had been returned to food for $4 \mathrm{wk}$ (Period 2), there was no longer an influence of treatment on critical swimming speeds for walleye pollock $\left(t_{18}=0.899, p=0.381\right.$, detectable effect size at power $0.8=8$ ), but sablefish that had been previously deprived continued to have a reduced capacity for swimming activity $\left(t_{14}=2.512, \mathrm{p}=0.026\right)$. In Period 3 there was no treatment effect on critical swimming speed for walleye pollock $\left(t_{17}=1.701, \mathrm{p}=0.108\right.$, detectable effect size at power $0.8=10$ ); sablefish could not be tested in our chamber due to their large body size.

\section{DISCUSSION}

As predicted, walleye pollock and sablefish clearly differed in their capacity to compensate for a period of
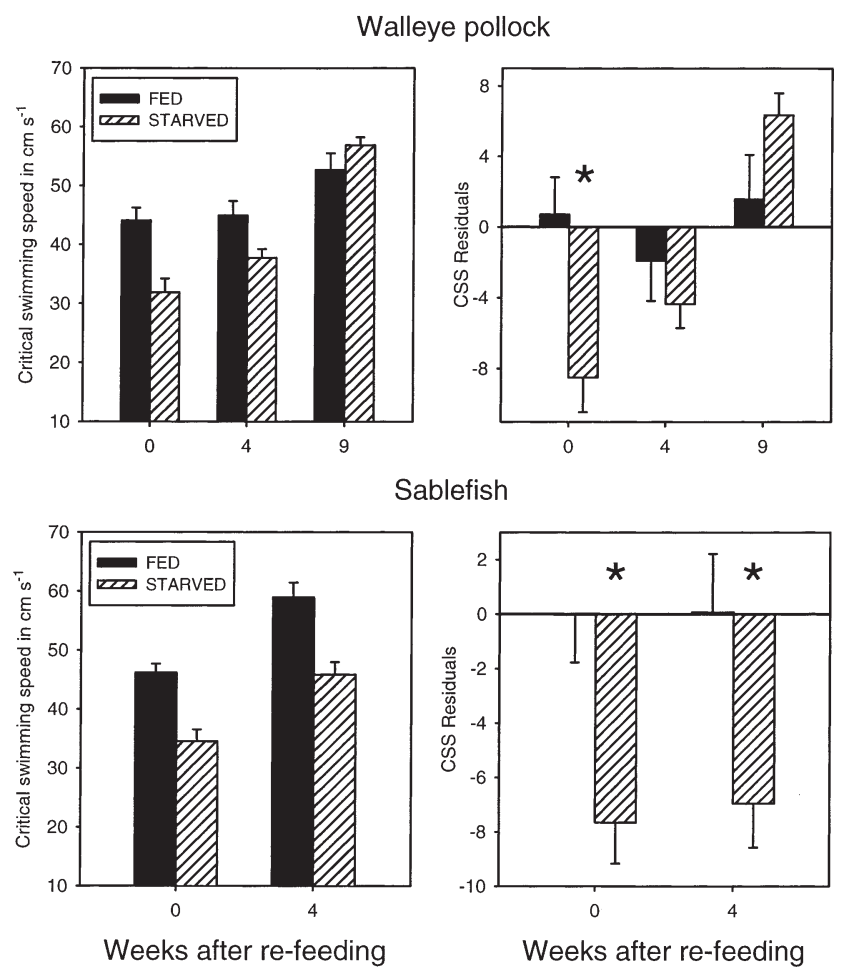

Fig. 11. Theragra chalcogramma and Anoplopoma fimbria. Mean critical swimming speed (SE) and residuals after adjusting for body size for walleye pollock and sablefish. *: significant differences between treatments (only residual scores were tested) within a time period based on $t$-tests. Fish were either held on ad libitum rations prior to the experiment (solid bars) or held without food for 2 to $3 \mathrm{wk}$, then returned to ad libitum rations (striped bars). Experiments were conducted 0 , 4 , and 9 wk after deprived fish were returned to ad libitum rations. Sablefish were too large after $9 \mathrm{wk}$ of re-feeding to allow testing in the swimming chamber

reduced growth. Deprived walleye pollock markedly accelerated their rate of growth in weight immediately after food was provided and were able to maintain a significantly faster growth rate than control fish for the next 9 wk. Growth in length initially lagged behind control fish, but subsequently accelerated to substantially faster rates for Weeks 4 to 12 after re-feeding. Deprived sablefish displayed only a minimal capacity for compensatory growth, with smaller fish (1998 experiment) more likely to accelerate growth than larger fish (1995 experiment). Significantly faster growth in weight (after adjusting for initial size) by deprived sablefish compared to controls occurred only during 1 time period in each experiment; faster growth in length occurred during 4 time periods in 1998 but was not evident in 1995.

Proximate factors underlying the difference in capacity for compensatory growth between the 2 species appear to be related to physiology. Walleye pollock were able to accelerate growth by greatly increasing their consumption rates compared to control fish, 
but compensating sablefish may not have been able to exceed the already high consumption rates of continually fed controls. Instead, the slight compensation displayed by sablefish appeared to be derived from a shift in resource allocation, resulting in a reduced physiological capacity for forced swimming. Although several studies have found reduced critical swimming speeds in fast-growing fish (Kolok \& Oris 1995, Farrell et al. 1997, Gregory \& Wood 1998, Billerbeck et al. 2001), the underlying mechanism is unclear. Presumably additional energy is allocated to tissue synthesis in compensating individuals, reducing the scope for swimming activity compared to non-compensating fish. More detailed studies of metabolic rates and potential shifts in the distribution of available energy among competing physiological functions for compensating individuals are needed to define the processes impacted by this trade-off.

Under non-compensatory conditions, sablefish maintain extremely rapid growth via high consumption, with a moderate conversion efficiency comparable to that exhibited by other teleosts (Sogard \& Olla 2001). Bluefish Pomatomus saltatrix is another species exhibiting rapid growth rates but moderate conversion efficiency (Juanes \& Conover 1994) and a limited capacity to engage in compensatory growth (Buckel et al. 1998), suggesting a juvenile growth strategy similar to that of sablefish. For these 2 species the balance between costs and benefits of rapid growth appears to be shifted toward the benefits extreme. One potential explanation is that the intensity of size-selective predation is greater for these species than for those that appear to exhibit more risk-averse foraging behavior. This hypothesis could be tested by comparing the degree of size-selective predation in field populations. The role of size-dependent mortality is evident within a species for Menidia menidia, where the greater intensity of overwinter mortality in northern locations has selected for faster baseline growth rates compared to southern populations (Schultz et al. 1998).

Our experiments were conducted during 3 periods to track the time course of fish engaged in compensatory behavior. Period 1 evaluated behavior immediately after deprivation. Reduced routine swimming speeds and reduced critical swimming speeds for both species at this time could have been a consequence of lower overall condition, but the much higher consumption rate of deprived walleye pollock compared to control fish indicates the initiation of a compensatory mechanism. Period 2 experiments were intended to measure behavioral responses of fish that had recovered in body weight and were actively engaged in compensatory growth under conditions of unlimited food availability. The 2 species used different mechanisms to achieve faster growth at this time. Previously deprived walleye pollock continued to have reduced routine swimming speeds and higher consumption rates, but similar critical swimming speeds compared to control fish, whereas deprived sablefish continued to have reduced critical swimming speeds but did not differ in behavioral responses from control fish. By Period 3, the absence of treatment effects for walleye pollock suggests that compensatory behavior had diminished after 9 wk of foraging on ad libitum rations. Because the large size of sablefish by Period 3 prohibited our use of the swimming chamber, we do not know if swimming capacity was still inhibited at this time.

These behavioral and physiological responses to prior food deprivation provide evidence of the capacity for the 2 species to induce potential compensatory mechanisms, but their initiation may depend on the environmental conditions to which fish are exposed. For example, in the field walleye pollock may not be able to both increase consumption and decrease routine swimming speeds if finding more prey requires heightened searching behavior. Likewise, we did not test other possible mechanisms allowing shifts in behavior or energy allocation. For example, compensating fish may have achieved faster growth by improving conversion efficiency (Qian et al. 2000). Our results are suggestive of trade-offs that differ between the 2 species, but do not exclude additional responses that may be similar. In the field, further requirements of avoiding predators, maintaining appropriate physical conditions and finding sufficient prey may modify the type and extent of compensatory mechanisms induced to accelerate growth.

Responses to the simulated predation threat in the behavioral experiments did not differ between control and deprived fish during any of the observation periods, counter to our prediction that compensating fish would be more risk-prone. Although our prior work with walleye pollock has demonstrated a significant effect of a similar threat on group cohesion (Sogard \& Olla 1997), consistent effects on proximity to the feeder and routine swimming were not evident in this study. The higher consumption rate of previously deprived walleye pollock is consistent with greater risk-taking compared to control fish, but our behavioral measures were possibly not sensitive enough to detect a treatment effect. Sablefish clearly responded to the simulated threat, but control fish recovered at similar or faster rates than previously deprived fish. This result is consistent with our conclusion that physiological rather than behavioral mechanisms are used by sablefish to achieve their modest level of accelerated growth. However, definitive assessment of risk-taking by compensating individuals of either species would require more extensive comparisons of behavioral responses potentially influenced by predators. 
Results of this study and those conducted on other species suggest a flexibility in mechanisms employed by teleosts to generate compensatory growth. For example, walleye pollock were able to accelerate growth with no apparent reduction in physiological capacity as indexed by critical swimming speed, and sablefish were able to grow faster without increasing consumption. Compensating gibel carp Carrasius auratus gibelio were able to increase conversion efficiency without any change in general motor activity (Qian et al. 2000). Compensatory behavior differed for Atlantic salmon whose growth was restricted via food limitation compared to those with growth inhibited by cold temperatures (Nicieza \& Metcalfe 1997). Associated tradeoffs also presumably vary among different compensatory mechanisms. Increased food consumption, as observed for walleye pollock, may entail a higher risk of predation due to increased exposure and reduced vigilance (e.g. Godin 1986, Metcalfe et al. 1987, Morgan 1988). A physiological trade-off of reduced swimming capacity, as observed in sablefish, may also increase predation risk, but as a consequence of impaired escape abilities (e.g. Lankford et al. 2001).

In conclusion, we have demonstrated broadly different capacities for compensatory growth in juveniles of 2 North Pacific fish species, and different mechanisms providing for accelerated growth. The results suggest contrasts in the costs of rapid growth between the 2 species. At the evolutionary scale there has clearly been strong selection pressure for rapid baseline growth in juvenile sablefish, yet even in this species there is some reserve maintained that allows a modest level of compensation. Walleye pollock maintain a more moderate growth rate under normal conditions, but can generate much faster growth if needed. To understand these differences in growth capacity and the behavioral and physiological costs of accelerating growth, we need further information on the processes that govern the timing and form of size-dependent mortality in the field.

Acknowledgements. We thank Mara Spencer, Erick Sturm, Michele Ottmar, Rich Titgen, and Amy Chiachiolo for assistance with experiments and videotape analysis. Al Stoner and Marc Mangel provided careful reviews of an early draft of the manuscript.

\section{LITERATURE CITED}

Arendt JD (1997) Adaptive intrinsic growth rates: an integration across taxa. Q Rev Biol 72:149-177

Billerbeck JM, Lankford TE Jr, Conover DO (2001) Evolution of intrinsic growth and energy acquisition rates. I. Tradeoffs with swimming performance in Menidia menidia. Evolution 55:1863-1872

Brett JR (1964) The respiratory metabolism and swimming performance of young sockeye salmon. J Fish Res Board Can 21:1183-1226

Buckel JA, Letcher BH, Conover DO (1998) Effects of delayed onset of piscivory on the size of age- 0 bluefish. Trans Am Fish Soc 127:576-587

Campana SE (1996) Year-class strength and growth rate in young Atlantic cod Gadus morhua. Mar Ecol Prog Ser 135: $21-26$

Conover DO, Schultz ET (1997) Natural selection and the evolution of growth rate in the early life history: what are the trade-offs? In: Chambers RC, Trippel EA (eds) Early life history and recruitment in fish populations. Chapman \& Hall, New York, p 305-332

Damsgaard B, Dill LM (1998) Risk-taking behavior in weightcompensating coho salmon, Oncorhynchus kisutch. Behav Ecol 9:26-32

Farrell AP, Bennett W, Devlin RH (1997) Growth-enhanced transgenic salmon can be inferior swimmers. Can J Zool 75:335-337

Godin JGJ (1986) Risk of predation and foraging behaviour in schooling banded killifish (Fundulus diaphanus). Can J Zool 64:1675-1678

Gregory TR, Wood CM (1998) Individual variation and interrelationships between swimming performance, growth rate, and feeding in juvenile rainbow trout (Oncorhynchus mykiss). Can J Fish Aquat Sci 55:1583-1590

Gregory TR, Wood CM (1999) Interactions between individual feeding behavior, growth, and swimming performance in juvenile rainbow trout (Oncorhynchus mykiss) fed different rations. Can J Fish Aquat Sci 56:479-486

Hare JA, Cowen RK (1997) Size, growth, development and survival of the planktonic larvae of Pomatomus saltatrix (Pisces: Pomatomidae). Ecology 78:2415-2431

Houde ED (1987) Fish early life dynamics and recruitment variability. Am Fish Soc Symp 2:17-29

Jobling M, Meloy OH, Santos J dos, Christiansen B (1994) The compensatory growth response of the Atlantic cod: effects of nutritional history. Aqua Intl 2:75-90

Juanes F, Conover DO (1994) Rapid growth, high feeding rates, and early piscivory in young-of-the-year bluefish (Pomatomus saltatrix). Can J Fish Aquat Sci 51:1752-1761

Kolok AS, Oris JT (1995) The relationship between specific growth rate and swimming performance in male fathead minnows (Pimephales promelas). Can J Zool 73: 2165-2167

Lankford TE Jr, Billerbeck JM, Conover DO (2001) Evolution of intrinsic growth and energy acquisition rates. II. Tradeoffs with vulnerability to predation in Menidia menidia. Evolution 55:1873-1881

Leggett WC, DeBlois E (1994) Recruitment in marine fishes: is it regulated by starvation and predation in the egg and larval stage? Neth J Sea Res 32:119-134

Lima SL, Dill LM (1990) Behavioral decisions made under the risk of predation: a review and prospectus. Can J Zool 68: 619-640

McCarthy ID, Houlihan DF, Carter CG (1994) Individual variation in protein turnover and growth efficiency in rainbow trout Oncorhynchus mykiss (Walbaum). Proc R Soc Lond B 257:141-147

Meekan MG, Fortier L (1996) Selection for fast growth during the larval life of Atlantic cod Gadus morhua on the Scotian Shelf. Mar Ecol Prog Ser 137:25-37

Metcalfe NB, Huntingford FA, Thorpe JE (1987) The influence of predation risk on the feeding motivation and foraging strategy of juvenile Atlantic salmon. Anim Behav 35:901-911

Miller TJ, Crowder LB, Rice JA, Marschall EA (1988) Larval 
size and recruitment mechanisms in fishes: toward a conceptual framework. Can J Fish Aquat Sci 45:1657-1670 Morgan IJ, McCarthy ID, Metcalfe NB (2000) Life-history strategies and protein metabolism in overwintering juvenile Atlantic salmon: growth is enhanced in early migrants through lower protein turnover. J Fish Biol 56:637-637

Morgan MJ (1988) The influence of hunger, shoal size and predator presence on foraging in bluntnose minnows. Anim Behav 36:1317-1322

Nicieza AG, Metcalfe NB (1997) Growth compensation in juvenile Atlantic salmon: responses to depressed temperature and food availability. Ecology 78:2385-2400

Qian X, Cui Y, Xiong B, Yang Y (2000) Compensatory growth, feed utilization and activity in gibel carp, following feed deprivation. J Fish Biol 56:228-232

Roff DA (1992) The evolution of life histories. Chapman \& Hall, New York

Schultz ET, Conover DO, Ehtisham A (1998) The dead of winter: size-dependent variation and genetic differences in

Editorial responsibility: Kenneth Heck (Contributing Editor), Dauphin Island, Alabama, USA seasonal mortality among Atlantic silverside (Atherinidae: Menidia menidia) from different latitudes. Can J Fish Aquat Sci 55:1149-1157

Sogard SM (1994) Use of suboptimal foraging habitats by fishes: consequences to growth and survival. In: Stouder DJ, Fresh KL, Feller RJ (eds) Theory and application in fish feeding ecology. Belle W. Baruch Press, Columbia, SC, p 103-131

Sogard SM (1997) Size-selective mortality in the juvenile stage of teleost fishes: a review. Bull Mar Sci 60: $1129-1157$

Sogard SM, Olla BL (1997) The influence of hunger and predation risk on group cohesion in a pelagic fish, walleye pollock Theragra chalcogramma. Env Biol Fish 50: $405-413$

Sogard SM, Olla BL (2001) Growth and behavioral responses to elevated temperatures by juvenile sablefish (Anoplopoma fimbria) and the interactive role of food availability. Mar Ecol Prog Ser 217:121-134

Submitted: October 3, 2001; Accepted: July 18, 2002

Proofs received from author(s): October 21, 2002 